\title{
Técnica de los cuentos de Manuel Gutiérrez Nájera
}

\author{
II \\ C. TIPOS HUMANOS : HOMBRES, MUJERES \\ $\mathrm{Y}$ NINOS
}

Caracteres generales. Los personajes de Gutiérrez Nájera son un reflejo de su concepto de la humanidad, siempre subjetivo, siemFre emotivo. Le atraen ciertos tipos humanos que se repiten, limitando el alcance de su mundo poblado a determinadas caracterizaciones.

Rasgos exteriores. Conforme al género de la narración corta, el autor evita descripciones detalladas del aspecto físico de sus personajes. En algunos cuentos omite por completo indicaciones del aspecto físico, como en La pasión de Pasionaria, en Cuento triste y en Un 14 de julio. Cuando las hay, no siempre sigue el modo rutinario de descripción del personaje al principio de la narración, pero intercala algunos rasgos a la manera de pinceladas accidentales de un pintor aquí y allá, mientras se desliza el cuento; por ejemplo, en $L a b a$ lada de año nuevo, situando el escenario de la alcoba donde está muriendo el bebé en la presencia de su angustiada madre, no presenta ningún rasgo del moribundo en el primer párrafo, pero poco a poco revela las características del bebé por medio de la acción. Averiguamos gradualmente de su blanco pecho, de sus labios pálidos y marchitos, de sus manecitas frías, de sus graciosos hoyuelos en los codos, de sus ojos negros y cabellos rubios y de sus deditos amarillos, rasgos todos comunes a un infinito número de bebés, pero que en este 
cuento intensifican la amargura por la pérdida de la preciosa vida que se va fatalmente y que humanizan el curso de la trama.

En general, no hay nada distintivo en el aspecto físico de los personajes de Gutiérrez Nájera, quien, al parecer, no concede mucha importancia a este aspecto, puesto que se limita a proporcionar casualmente rasgos físicos comunes, y esto sólo de algunos de los personajes y ni siquiera en la producción entera; así, por ejemplo, en el cuento más extenso, Juan el organista, tiene a bien el Duque bosquejar concisamente al protagonista: "Tendría treinta años y era de regular figura, ojos expresivos, traje limpio, aunque pobre, $y$ finos modales." 57

En cuanto a las jóvenes protagonistas, basta al autor caracterizarlas de "bonitas". Algunas veces da un paso adelante, añadiendo más rasgos, como en la Crónica de mil colores, cuya heroína, la " $\mathrm{Ca}$ perucita color de rosa", se presenta con un orden de adjetivos más amplio:

A los trece años, nuestra heroína ya no era una niña; tenía el talle fino y bien formado, el seno blanco, los ojos grandes y negros, y las manos blancas y pequeñitas. 58

Sólo en La novela del tranvía, cuyo asunto está completamente fantaseado sobre la base de la apariencia exterior de dos personajes, hace *I autor una excepción, describiéndolos con acertados detalles, act1diendo a su vivo sentido de observación y chispeante agudeza. Así reacciona ante el aspecto de su vecino de tranvía:

Un viejo de levita color de almendra meditaba apoyado en el puño de su paraguas. No se había rasurado. La barba le crecía, "cual ponzoñosa hierba entre arenales." Probablemente no tenia en su casa navajas de afeitar... ni una peseta. Su levita necesitaba aceite de bellotas. Sin embargo, la calvicie de aquella prenda respetable no era prematura, a menos que admitamos la teoría de aquel joven poeta, autor de ciertos versos cuya dedicatoria es como sigue:

\section{A LA PREMATURA MUERTE DE MI ABUElita}

A LA EDAD DE NOVENTA AÑos

La levita de mi vecino era ya muy mayor. En cuanto al paraguas, vale más que no entremos en dibujos. Ese paraguas, expuesto a la intemperie, debía asemejarse mucho a las banderas que los independientes sacan a la luz el 15 de Septiembre. Era un para- 
guas calado, un paraguas metafísico, propio para mojarse con decencia. Abierto el paraguas, se veía el cielo por todas partes. 69

Más juguetona todavía es la descripción de la dama que ocupa el asiento del viejecito:

En el asiento que antes ocupaba el cesante, descansa ahora una matrona de treinta años. No tiene malos ojos; sus labios son gruesos y encarnados: parece que los acababan de morder. Hay en todo su cuerpo bastantes redondeces y ningún ángulo agudo. Tiene la frente chica, lo cual me agrada, porque es indicio de tontera; el pelo negro, la tez morena y todo lo demás bastante presentable. ¿Quién será? Ya la he visto en el mismo lugar y a la misma hora dos... cuatro... cinco... siete veces. Siempre baja del vagón en la plazuela de Loreto y entra en la iglesia. Sin embargo, no tiene cara de mujer devota. No lleva libro ni rosario. Además, cuando llueve a cántaros, como está lloviendo ahora, nadie va a novenarios ni sermones. Estoy seguro de que esa dama lee más novelas de Gustavo Droz, que el "Menosprecio del Mundo", del padre Kempis; tiene una mirada, que si hablara sería un grito pidiendo bomberos. Viene cubierta con un velo negro. De esa manera libra su rostro de la lluvia. Hace bien. Si el agua cae en sus mejillas, se evapora chirriando, como si hubiera caído sobre un hierro candente. Esa mujer es como las papas; no se fien ustedes, aunque las vean tan frescas en el agua: queman la lengua. 60

Apelativos. A diferencia de otros cuentistas que dan apellidos a sus protagonistas, muchas veces en conformidad con su personalidad, Gutiérrez Nájera no suele apellidar a sus personajes. Hay excepción clara para un apellido simbólico, que se conforma con la personalidad del sujeto, el del viejo barón de Saint-Loup y su hijo Avenant de Saint-Loup (Crónica de mil colores). Además de éste, se encuentran sólo tres apellidos en la producción entera de cuentos: D. Pedro Anzúrez (Juan el organista), padre de Enriqueta, el cual es un personaje sin importancia, Carlos Saldaña, inquilino en expectativa de la corta comedia El alquiler de una casa, y Teófilo Pomar (El músico de la murga), personaje adoptado de Federico Gamboa.

Prefiere el autor dejar por completo anónimos a los protagonistas de cuatro cuentos: el suicida (Los suicidios), la francesita (Historia de una corista), la mexicanita y su marido francés ( $U n$ n 14 de julio), la niña hija de Adrián (El vestido blanco), y los de los 
cuentos epistolares, el suicida (Los suicidios) y la francesita (Historia de una corista).

Para identificar a sus personajes el Duque les pone nombres tomados al azar dentro de los que se encuentran a diario entre las gentes, o, más característicamente, les da apodos, o les pega alguna identificación, típica de su personalidad.

Nombres masculinos: Juan (La pasión de Pasionaria) ; Adrián (El vestido blanco); Pedro (Dame de coeur); Enrique (Cuento triste); Pablo (La balada de año nuevo).

Nombres femeninos: Clara, Alicia (La venganza de Mylord); Berta, Manón (Después de las carreras) ; Andrea, Antonia (La pasión de Pasionaria) ; Luz (Rip-Rip) ; Rosa, Enriqueta (Juan el organista); Rosa-Thé (Dame de coeur); Clara (La balada de año nuevo).

Nombres infantiles: Rosalía (La pasión de Pasionaria); Rosita (Juan el organista); Gabriel y Carlos (La mañana de San Iuan).

Apodos: Rip-Rip (cuento del mismo nombre); Juan el organista (cuento del mismo nombre); Caperucita color de rosa (Crónica de mil colores); Blanca (Cuento triste); Pasionaria (La pasión de Pasionaria); inglés, francesa (Historia de un peso falso); la Hija del aire (cuento del mismo nombre).

Apelativos descriptizos: el (músico) de los ojos azules desteñidos, el de levitón café y sombrero alto como de pizarra negra ( $E l$ músico de la murga); el caballero (Historia de un peso falso); Juan el del molino (Rip-Rip); Bebé (La balada de año nuevo).

Rasgos espirituales. Concepto general. Los límites de la narración corta no permiten una delineación de carácter completa como se requiere en una novela. Hay muchas facetas de personalidad humana que no interesan a Gutiérrez Nájera al grado suficiente para cincelarlas en sus obras. Sus protagonistas comunican al lector sólo ciertos rasgos personificados. No sabemos cómo trabajan, qué clase de ciudadanos son, no conocemos sus capacidades intelectuales. Lo que sí nos comunican es su vida emotiva en el dominio de pasiones, sobre todo las amorosas y su proceder en el hogar, esferas de la vida humana que llenan todo el ser del propio escritor. 
En el análisis de los cuentos individuales hecho en el capítulo Iv hemos sacado a luz la propensión dominante de los tipos de Gutiérrez Nájera hacia la incapacidad abrumadora de hacer frente a las crisis emotivas. La humanidad de Gutiérrez Nájera es una humanidad sufriente, infeliz, ardientemente pasional, que fatalmente camina al fracaso. No hay línea de demarcación definitiva entre las características masculinas y femeninas. Los rasgos de ambas se funden en la misma norma humana, capaz de comunicarse a ambos sexos.

Hombres. Los hombres de Gutiérrez Nájera son portavoces del propio autor. No crea la variedad de tipos masculinos que existe en la vida, sino que traslada a sus héroes su propia alma, haciéndolos representar las diferentes facetas de su personalidad. Juan el organista es un infeliz amante; Adrián (El vestido blanco) y Pablo (La balada de año nuevo) son amorosos padres; Pedro (Dame de coeur) y Enrique (Cuento triste) son unos infaustos adictos a vicios; el suicida (Los suicidios) es un desilusionado de la fe; los músicos (El muisico de la murga) son desventurados esclavos de tareas rutinarias, obligados a prostituir su arte, tocando para bailes populares.

Además de estos caracteres, hay algunos personajes convencionales de la época romántica, dispersos en varios cuentos: un viejo libertino y su tímido y suspirante hijo romántico (Crónica de mil colores); un marido ultrajado (Rip-Rip); un marido sin voluntad, dominado por su malvada mujer (La pasión de Pasionaria). Los hombres de Gutiérrez Nájera en general son seres corrientes, tomados del ambiente de la clase media de México. No se destacan por originalidad de carácter, ni por sus facultades intelectuales, pero son humanos, poseen simpatía personal y atractivo sentimental.

Mujeres. La imagen de la mujer que moldea la imaginación del poeta es la de una heroína romántica, una mujer que forja la felicidad del hombre amado. Es la enamorada fascinante, la esposa fiel y la madre sacrificada. La actitud del Duque hacia la mujer se conciiciona, en parte, por las ideas dominantes de la época y del país donde vivía, y también por sus propias preferencias. No le atrae la mujer hombruna, ansiosa de competir con los hombres en terrenos políticos y profesionales. El poeta idealiza a la mujer, le concede extraordinaria importancia en la vida, pero dentro de la esfera que, 
según cree, corresponde al sexo femenino: el hogar. Gutiérrez Nájera es un convencido de la santidad del matrimonio y de la familia. Expresa extensamente sus ideas sobre el matrimonio y discurre sobre el tipo de mujer que admira en dos artículos: "E1 Matrimonio". Carta a Alfonso y "Las mujeres de talento." ${ }^{61}$ En el primero dice, después de reconvenir a su amigo por no querer casarse:

El matrimonio es una carga grave, $y$ tan grave, que la iglesia ha reconocido que se necesita la gracia de Dios para soportarla, y por eso ha instituido el Sacramento. Yo acepto el matrimonio con todos sus inconvenientes, con todas sus desventajas; estimo por de irreprochable certidumbre aquel adagio de la India, que dice que "el hombre no se completa hasta que no es hombre, mujer y niño"; no me imagino un hogar en el que todo sea vida y dulzura; sé que los niños se enferman, que lloran y se desgañitan, que han menester médico y botica, que la esposa se pone vieja, que los negocios suelen embrollarse... y con todo esto te digo $y$ te aseguro que no me arrepiento de haber defendido el matrimonio, que lo defiendo y seguiré defendiéndolo, mal que te pese a ti y a tus iguales. 62

\section{$\mathrm{Y}$ continúa:}

... juzga, pues, si será grande mi amor por la mujer y por el matrimonio, cuando ni Balzac, ni Alphonse Karr, ni Gustavo Flaubert, ni Ernest Feydeau, han podido arrancar de mi conciencia la idea de la santidad de la familia. ${ }^{63}$

El Duque hace una distinción marcada entre la pasión y el amor. No cree en la eternidad de las pasiones, mientras que el amor, hermoso y divino, perdura aún después de la muerte:

No es menos cierto, como decía uno de mis amigos que tiene la singular idea de investigar el origen de las palabras más en las analogías que en las raíces, que la palabra pasión viene del verbo pasar. En efecto, si la pasión tiene por excusa el creer que es eterna, tiene por carácter ordinario y fatal el no serlo. Por grande que sea un incendio, por mucha que sea la luz con que ilumina el cielo, cualquiera que sea la extensión del espacio que devora, termina siempre por apagarse, $\mathrm{y}$ tanto cuanto ha brillado y consumido deja en ruinas y en desesperación, en soledad y en miseria. Tal es la pasión: devórase y consúmese en su propio fuego, mientras que el amor ocupa una vida toda, por larga que sea, y de tal suerte, que a la hora de la muerte queda aún bastante para llenar la eternidad. No, no habéis amado, si no habéis creído que después de la 
muerte ibais a amar siempre, eternamente joven, eternamente hermoso, al ser que amado hubísteis en la tierra. ${ }^{64}$

En el segundo artículo "Las mujeres de talento", el Duque revela su idea acerca de la mujer, discurriendo con detalles sobre sus preferencias y defendiendo con vehemencia su posición. No ve con ojos favorables a las llamadas "mujeres de talento", porque considera que la vocación de la mujer es lograr los fines del corazón y no los de la inteligencia:

¡Dios nos libre de las mujeres de talento! Aquella frase fué para mí un rayo de luz. Comprendi quienes son las mujeres que el vulgo llama de talento. i Vi clara y distintamente como entre las sabias y las necias hay un término medio, la mujer del hogar, la mujer eterna, verdadera y única, la mujer que ama! Para el vulgo, la mujer de talento es la mujer que está a un paso de convertirse en hombre. Sabe, escribe, habla, diserta, juzga; discute las controversias filosóficas; dirige los asuntos del Estado; puede levantarse en las academias; ir a la cátedra, manejar el escalpelo en el anfiteatro; pero, en cambio, no podrá ser una esposa querida, una madre buena, no sabrá amar; por consiguiente, tendrá el talento del hombre, que consiste en lograr los fines de la inteligencia; pero no el talento de la mujer, que consiste en lograr bs fines de su corazón. 65

Lamenta el Duque que el siglo xvirr fuera "el siglo de la mujer hecha hombre":

Madama Pompadour no era una mujer de talento. Madama Pompadour era un hombre de Estado. Yo no adivino alma femenil en este Richelieu con faldas, como tampoco la adivino en casi todas esas grandes damas del reinado de Luis XV. Aquel siglo XvII fúé el siglo de la mujer hecha hombre. 66

Discutiendo el poder que las mujeres ejercían en la Francia del siglo xviII, dice:

De un cabo a otro del siglo, el gobierno de la mujer es el único gobierno visible y sensible; es el gobierno de Madama de Prie; es el gobierno de Madama Mayli, es el gobierno de Madama de Chateauroux; es el gobierno de Madama Pompadour; es el gobierno de Madama Du Barry. Así como Darwin juzga en su teoría del transformismo que las especies se fueron metamorfoseando en evoluciones progresivas hasta que el mono se convirtió en hombre, en aquel siglo. 67 
La mujer realiza en la vida fines distintos de los que pertenecen al hombre:

Como la mujer viene a realizar en la vida fines muy diversos de los que viene a realizar el hombre, debe juzgarse de su inteligencia, con un criterio también distinto. Dios puso una gran parte del talento de las mujeres en el corazón. La ciencia de la mujer no consiste en amar, sino en saber amar; cuando hija, a sus padres; cuando esposa, a su esposo; cuando madre, a sus hijos. Cuando nosotros aprendemos a ser letrados, ellas deben aprender a ser madres. En la educación es donde debe ejercitarse la inteligencia. El hogar es una cátedra. Una madre buena, es una mujer de talento. La educación es un resultado de dos fuerzas unidas: la fuerza intelectual, que debe derivarse del padre, y la fuerza del amor, que nace de la mujer. 68

Gutiérrez Nájera no quiere que la mujer invada los dominios del hombre:

Yo no creo, como Lamartine, que el alma de la mujer sea superior a la del hombre. La creo perfectamente distinta. Por eso me enoja verla fuera de su órbita, invadiendo los dominios del hombre. Quiero mirarla en los hospitales, pero como hermana de la caridad, no como médico: El sacerdocio de la mujer es todo de amor y de consuelo. No cierro tampoco para ella las puertas de las letras y del arte; pero quiero que este arte sea como el de Madama de Sevigné, por ejemplo; la expresión bella del amor solícito de una madre. 69

En el arte le concede el lugar de inspiradora del hombre:

En el arte, el principal oficio de la mujer es el de inspiradora. Pocas concepciones bellas se han desarrollado sin su auxilio. Todos tenemos en el fondo de nuestro espíritu un ideal al que se adjustan nuestras creaciones. Hay una imagen querida en nuestra imaginación, que proyecta su sombra en el papel cuando escribimos. Ayer fué nuestra madre; hoy, nuestra novia; mañana, nuestra esposa; después, nuestra hija. Yo mismo, al trazar estas líneas, guardo en mi espíritu un ideal que me sonríe. Busco los secretos del talento en el océano negro de sus ojos. La virtud tiene para mí un nombre: el suyo. 70

Tan profunda es la admiración que el poeta siente por el alma femenina, que busca una imagen cuando escribe de la visita del Dante al infierno: 
¡Ah! no saquemos a la mujer de su esfera. Dejémosla en el hogar, y aprovechemos allí su imponderable fuerza. La necesitamos para atravesar la vida, como el cielo necesita las estrellas. Dante no se hubiera atrevido a bajar solo los círculos tenebrosos del infierno, por eso se acompañó de Virgilio, un alma femenil, como de poeta. 71

Para finalizar el artículo, Gutiérrez Nájera compara a dos mujeres: una dama inglesa que escribió tres volúmenes sobre la cuestión social en Inglaterra, y otra, conocida suya, que supo educar a sus hijos, y a ésta le otorga el laurel de supremacía:

Tengo a la vista una obra en tres tomos, escrita por una miss filósofa, sobre la cuestión social en Inglaterra. En cambio, conozco a una dama que nunca ha pensado en escribir disertaciones estadísticas, pero ha sabido educar a sus hijas. Si se me pregunta quién de las dos tiene más talento, contestaré sin vacilar que la segunda. Su obra es una obra en tres partes, que revela mucha más inteligencia, y sobre todo, más amor, que los tres volúmenes anti-socialistas de la dama inglesa. ${ }^{\mathbf{2}}$

En vista de ideas acerca de las mujeres, expresadas en los citados artículos, que en la época actual pueden parecer fuera de moda, queda en claro la concepción de las manifestaciones femeninas que inspiran al poeta en su obra artística. Enriqueta (Juan el organista), Rosa-Thé (Dame de coeur), Blanca (Cuento triste), todas ellas heroínas románticas, personifican rasgos de atracción femenina, de ternura sentimental, de dulzura de carácter, de capacidad de amor ilimitado y de sacrificio. Su fuerza se deriva de las facultades del corazón y no del cerebro. Cualidades de lo bello femenino poseen también Berta y Manón (Después de las carreras).

Ser madre buena es otra misión de la mujer. El ideal de la madre sacrificada lo personifican Andrea (La pasión de Pasionaria), la mexicanita ( Un 14 de julio), la madre de Gabriel y Carlos ( $L a$ mañana de San Juan), y Clara (La balada de año nuevo). Gutiérrez Nájera siempre aprovecha la oportunidad para rendir homenaje a la madre en términos de veneración exaltada. Llorando los suplicios de la "Hija del aire", rinde tributo al amor maternal que vence todos los obstáculos:

Di, pobre niña, ¿qué, no tienes madre? ¿ Naciste acaso de una pasionaria, o viniste a la tierra en un pálido rayo de la luna? Si 
tuvieras madre, si te hubieran arrebatado de sus brazos, ella, con esa adivinación incomparable que el amor nos da, sabria que aquí llorabas y sufrías; traspasando los mares, las montañas, vendría como una loca a libertarte de esta esclavitud, de este suplicio. No, no hay madres malas, es mentira. La madre es la proyección de Dios sobre la tierra. Tú eres huérfana. ${ }^{\mathbf{7 3}}$

La adoración que en el Duque hay al ideal de madre es tal que incluso para una madre de baja moralidad, entregada al alcoholismo, cual la madre del "inglesito" en la Historia de un peso falso, halla el sentimiento de ternura y de perdón en su corazón. Presentando al "inglesito", dice:

Por supuesto, no conocía a su padre... era uno de tantos pesos humanos, de esos que circulan subrepticiamente por el mundo y que ninguno sabe en dónde fueron acuñados. Pero a la madre, isi la conocía! Los demás decían que era mala. El creía que era buena. Le pegaba. ¡Ese sería su modo de acariciar! También cuando no se come, es imposible estar de buen humor. $Y$ muchas veces aquella desgraciada no comía. Sobre todo, era la madre; ilo que no se tiene más que una vez!, lo que siempre vive poco; la madre que, aunque sea mala, es buena a ratos, aquélla en cuya boca no suena el tú como un insulto... la madre, en suma... inada más la madre! 74

Sin embargo, Gutiérrez Nájera es demasiado realista para suponer que todas las mujeres sean virtuosas. En su galería de retratos femeninos hay una desalmada madrastra (La pasión de Pasionaria), la muchacha perversa que usa la coqueteria femenina para alcanzar sus fines mercenarios (Crónica de mil colores), y la mujer de dudosa vida que tampoco podría hacer alarde de sus virtudes (la francesita en la Historia de una corista).

Niños. A sus escritos lleva Gutiérrez Nájera los retratos de niños que se hallan fuertemente fijados en su imaginación. Le atraen el cutis blanco y los rizos rubios, ya que todos sus niños son rubios.

Del "inglesito" en la Historia de un peso falso dice: "Y parecía inglés, en verdad, porque era muy blanco, muy rubio, $y$ hasta habría sido bonito por no ser tan pobre." 75 Y a la niña de $E l$ vestido blanco la describe así: "Los azahares temblaban en sus rizos rubios; parecía una novia." ${ }^{76}$ Comentando las emociones de Juan el organista, después de abandonar a su esposa, observa : 
¡ Cómo sufría al oírla el pobre Juan! Iba a abrazarla en su camita, y mojando con lágrimas los rubios rizos y la tez sonrosada de la niña, le decía sollozando: ¡Pobrecita! ¡Somos huérfanos! 77

Describe el trágico ahogo de Carlos, en La mañana de San Juan: "Gabriel estaba rojo y sus manos sudaban, apretando la blanca manecita del hermano." $78 \mathrm{Y}$, cuando ya no hay remedio:

Ya se abren las aguas, como se abre la muchedumbre en procesión cuando la Hostia pasa. Ya se cierran y sólo queda por un segundo, sobre la onda azul un bucle lacio de cabellos rubios. ${ }^{79}$

Para el moribundo Bebé en La balada de año nuevo tiene mucha ternura: "El doctor ha auscultado el blanco pecho del enfermo; con sus manos gruesas toma las manecitas diminutas del pobre ángel ... ${ }^{80}$

Pablo, el padre del Bebé "llega, mira la cara del doctor y las manos enclavijadas de la madre; pero se tranquiliza: el ángel rubio duerme aún en su cuna -i no se ha ido!"- ${ }^{81} \mathrm{La}$ "Hija del aire" es de cabellos rubios :

Es una niña. Sus delgados bracitos van tal vez a quebrarse; su cuello va a troncharse y la cabeza rubia caerá al suelo, como un lirio cuyo delgado tallo tronchó el viento...

A ratos, sólo alcanzo a ver una flotante cabellera rubia, suelta como la de Ofelia, que da vueltas y vueltas en el aire. 82

Los niños de Gutiérrez Nájera piensan bien y exhiben madurez mental por encima de sus años. $\mathrm{El}$ pequeño Carlos en La mañana de San Juan habla a su hermanito Gabriel como un adulto, antes de ahogarse. ${ }^{83} \mathrm{El}$ "inglesito", en la Historia de un peso falso, y el Bebé, en La balada de año nuevo, son muy considerados y atentos para sús años.

Los niños del Duque son desdichados, salvo la niña de $E l$ vestido blanco, cuya vida real no aparece en el cuento. Ninguno goza de vida sana, ni feliz. Unos mueren, como los niños, en Un 14 de julio; Carlos, en La mañana de San Juan; el Bebé, en La balada de año nuevo, y otros intervienen en hechos trágicos, como Rosita, en Juan el organista, cuando, huérfana de madre, presencia la prematura muerte de su padre; la "Hija del aire" lleva una vida de tortura físi- 
ca y espiritual, ejecutando tramoyas peligrosas en el trapecio que le quiebran los huesos, y el "inglesito", en la Historia de un peso falso, está quebrantado por completo por la jugarreta del caballero que le arroja a la Correccional, desde donde asoma como espectro la vida del futuro criminal.

D. CONTRASTE ENTRE EL CUENTO DE GUTIERREZ NAJERA Y ALGUNOS CUENTOS TIPICOS DE OTRAS LITERATURAS DEL SIGLO XIX

1. The Gold-Bug (El escarabajo de oro) de Edgar Allan Poe; 2. El pájaro verde, de Juan Valera; 3 . The Sire de Malétroit's Door (La puerta del señor de Malétroit), de Robert Louis Stevenson; 4. La ficelle (La cuerdecita), de Guy de Maupassant; 5. Kryzhovnik ( La uva espín), de Antón Pávlovich Chéjov. ${ }^{84}$

Para hacer resaltar el sello personal de los temas de Gutiérrez Nájera y de su trayectoria, conviene ojear cuáles inspiran a otros cuentistas, considerados maestros en la narración corta. Coordinando la variedad de giros en las obras que caracterizan a cada autor, se aprecia la aportación que lleva Gutiérrez Nájera al cuento.

1. The Gold-Bug (El escarabajo de oro), de Edgar Allan Poe (1809-1849). Este cuento es una muestra del asunto que representa un problema resuelto matemáticamente. Los personajes que en él figuran no son sino bolos que mueven el juego a un feliz desenlace. La suspensión se basa en los pasos sucesivos que se toman por Legrand en el curso de la trama para desenredar el complicado nudo de las cifras, aparecidas en el pergamino bajo la influencia del calor. Aparentemente, un tema semejante no habría de entrar en la mente de Gutiérrez Nájera para poner en movimiento la chispa creadora de su imaginación. En este cuento no hay acción y reacción de sentimientos humanos ni problemas de personalidad, elementos indispensables en la obra del cuentista mexicano.

2. El pájaro verde, de Juan Valera y Alcalá Galiano. Es un cuento de hadas, desarrollado en un exótico ambiente oriental. Brilla en él la fantasía, el buen gusto y la elegancia de estilo del escritor. Gutiérrez Nájera que se empapó en las mejores tradiciones de la 
literatura española, refleja iguales características en su prosa creadora. El ambiente de lo fantástico y sobrenatural también le fascina como a un artista de nutrida imaginación y desempeña un papel importante en su obra, junto con los elementos realistas del complicado laberinto de relaciones humanas. El Duque no escribió ni un acabado cuento de hadas. La Crónica de mil colores, cuyo tema es la adaptación de la Caperucita roja, no puede considerarse un cuento de hadas por carecer del elemento fantástico, pero es más bien un estudio psicológico, labrado dentro de un marco caricaturesco del cuento tradicional. Empero, el elemento sobrenatural está intercalado en otros cuentos del Duque, cuando se le antoja hacerlo, como hemos visto en La pasión de Pasionaria, en Rip-Rip y en Después de las. carreras. ${ }^{85}$

3. 'The Sire de Malétroit's Door (La puerta del señor de Malétroit), de Robert Louis Balfour Stevenson (1850-1894). Este cuento revela la gran maestría de Stevenson al manejar la situación romántica en que su voluntad ha de meter a los protagonistas. Difiere de la obra de Gutiérrez Nájera por el marco de la época medieval (1429) y por el gran pulimento del proceder que se destaca sobre manera en la dificilisima situación, creada por el propio Stevenson, cuando los dos jóvenes, primero renuentes a la idea del casamiento, él atrapado contra su voluntad y ella enamorada de otro, terminan por enamorarse ambos de manera lógica y fatal.

Además, en toda la extensión del cuento, no hay ni una palabra que denote la presencia del autor, mientras que en los cuentos de Gutiérrez Nájera el autor siempre interviene y, en ocasiones, con gran vehemencia.

4. La ficelle (La cuerdecita), de Henri René Albert Guy de Maupassant (1850-1893). El cuento es una presentación brutal de la dureza humana. Un caso de acusación infundada, parecido al de $L a$ ficelle, y que también destruye a su víctima, se halla en la Historia de un peso falso. Gutiérrez Nájera, apasionado admirador de la literatura francesa, muestra su influencia. Entusiasta de Maupassant, publica sus cuentos en la Revista azul. ${ }^{86}$ Sin embargo, comparando a los dos escritores se aprecian diferencias en el desenvolvimiento de temas. Maupassant no moraliza, no predica. Es completamente objetivo. Nunca revela su propia actitud. Representa la vida tal como 
sus observaciones se lo indican, sin piedad ni compasión, escogiendo por temas las pasiones elementales. Es lacónico en su estilo. Evita las delicadezas y los refinamientos estilísticos, tan de gusto del Duque. Este no es nada brutal cuando presenta los aspectos trágicos de la vida, suele moralizar y predicar. Es subjetivo en extremo, acusa, elogia, entona plegarias, hace patente su generosidad, su compasión por la sufriente humanidad, se sirve de divagaciones líricas e incluso, melodramáticas, cualidades que dejamos indicadas antes, al analizar sus cuentos en el capítulo IV.

5. Kryzhovnik (La uva espín), de Antón Pávlovich Chéjov (1860-1904). Chéjov encierra la narración en un bello marco del campo ruso en el verano, cuando los convidados se reúnen en un salón de ambiente tradicional, después de haber gozado de un rato de natación en la laguneta privada de su hospitalario anfitrión. En este cuento, a diferencia de la técnica de Gutiérrez Nájera, Chéjov no lanza su "yo", no intercala sus miras, no interrumpe la narración con sus observaciones. En las descripciones del paisaje nunca acude a las personificaciones antropomórficas, como suele emplearlas el Duque. Hay mucho filosofismo crítico por parte del hermano del protagonista, pero de carácter social y no el de un "yo" herido, tan típico de Gutiérrez Nájera. Chéjov, a diferencia de Gutiérrez Nájera, solía hacer bosquejos de sus cuentos, apuntando el plan inicial, sobre el cual construía el argumento más tarde. ${ }^{87}$

\section{E. ELEMENTOS IDIOSINCRASICOS}

1. Fantasia. Este elemento abunda en los cuentos de Gutiérrez Nájera. La novela del tranvía es un ejemplo de cómo el autor es capaz de fantasear asuntos novelescos sin más datos que la impresión fugaz, captada en unas miradas a los personajes.

La manifestación de fantasía, que frecuentemente se halla en las páginas del Duque y en que el autor logra inusitada maestría, es la personificación del mundo físico. En el análisis de Juan el organista tuvimos ocasión de citar la descripción del volcán Ixtaccíhuatl "la mujer blanca.", que adquiere características femeninas en la imaginación del artista, con un toque de su acostumbrado erotismo: 
Es necesario que la luz, sirviendo de obediente camarera, descorra el pabellón de húmeda gasa para que veamos a los dos colosos. "La mujer blanca" se ruboriza entonces como recién casada a quien algún importuno sorprende en el lecho. Diriase que con la mórbida rodilla levanta las sábanas y las colchas. 88

Un ejemplo sobresaliente de la humanización de un objeto material, la de un peso falso, se presenta en la Historia de un peso falso. La fantasía del autor no vivifica en la figura de un vanidoso caballero: "Aquel peso era un peso teñido: su cabello era castaño, de cobre, y él por coquetería, porque le dijeran 'es Ud. muy Luis XVI' se lo había empolvado." 89

En Los amores del cometa el vuelo de fantasía del Duque cobra formas aún más atrevidas. En este cuento fantástico comunica rasgos antropomórficos a los astros del universo que languidecen en un estado de amor voluptuoso. $\mathrm{El}$ cometa es un Don Juan errante que anda por el cielo en busca de aventuras que hacen desternillar de risa a las siete cabrillas. Espía por la cerradura del Oriente las morbideces de las formas de la divina rubia, Aurora, que cándidamente sale de su lecho nupcial para arreglar su tocado. Las estrellas son doncellitas enamoradas, que quieren atrapar al cometa por pura coquetería. ${ }^{90}$

En Después de las carreras se le antoja al artista añadir toques de elemento sobrenatural, para crear un ambiente romántico y soñador, cuando pinta a la hermosa Berta, que se recostó en su perfumado lecho, dichosa con sus ensueños de rebosante juventud:

En la caliente alcoba se escuchaban nada más, los pasos sigilosos de los duendes que querían ver a Berta adormecida y el tictac de la péndula incansable, enamorada eternamente de las horas. 91

Y más adelante fantasea en un lenguaje más hechiçero aún:

Los duendes, que ansían verla dormida para besarla en la boca, sin que lo sienta, comienzan a rodearla de adormideras y a quemar en pequeñas cazoletas granos de opio. ${ }^{92}$

2. Filosofía. Entre los valores del Duque, que le proporcionan distinción como personalidad literaria, se destaca el aspecto epigramático. Esparcidos por toda la prosa, sus epigramas forman un cau- 
dal de pensamiento filosófico, que revela su concepto de la vida, sus actitudes hacia el sempiterno cambio de cosas mundanas, y su juicio sobre lo efímero de la contienda humana. Gutiérrez Nájera observa la vida mas no permanece indiferente frente a sus inconsistencias $e$ injusticias. La trayectoria que atravesó durante su corta encarnación estuvo llena de desengaños, de amargas desilusiones, a las cuales no siempre logró enfrentarse con serena impasibilidad. Busca soluciones y justificaciones del enigma de la vida, reacciona con vehemencia pasional. Las injusticias humanas le hacen sufrir profundamente, pero no degenera en cínico. Al verse rendido por la duda acude al Ser Supremo en anhelo de tranquilidad para el espíritu.

En su producción cuentística, el Duque dejó bastantes epigramas, intercalados en medio de la narración de la trama, y se sirvió de sus protagonistas como portavoces de su pensamiento filosófico.

La otra faceta del talento de Gutiérrez Nájera, la de su ático humorismo, también se revela ventajosamente en algunos graciosos epigramas.

Isaac Goldberg llama a los epigramas del Duque "afilados pensamientos "que pinchan como flechas." 93

$\mathrm{Y}$ Luis G. Urbina, comentando acerca de la variedad de facetas creadoras de su maestro, responde a su propia pregunta a Carlos Díaz Dufóo, en su artículo "Confidencias":

¿No recuerdas sus conferencias en la Prensa Asociada? Entonces se nos reveló un profundo pensador, a lo Buckle: iQué juicio, qué serenidad, qué alto criterio, qué observación personalísima de una arrebatadora originalidad! 94

Veamos los principales epigramas de Gutiérrez Nájera, siguiendo el orden de su aparición en los cuentos:

La venganza de Mylord:

...¿No amas? Amar es tener alas... ¿No amas? Amor es el perfume de las almas.

La lengua mata más que los puñales. 25

\section{En el hipódromo:}

Todo amor da la muerte.

El juego es la suprema sensación para aquellos que no conocen el amor, ese otro juego en que se apuesta el alma. ${ }^{96}$ 
La pasión de Pasionaria:

La gloria, sin sus hijos, no es gloria para una madre. ${ }^{97}$

Después de las carreras:

Hay mortajas de seda y ataúdes de palo santo, pero todos hormiguean y muerden los gusanos.

La seda se desgarra, el terciopelo se chafa, la epidermis se arruga con los años. Bajo la azul superficie de ese lago hay mucho lodo. Todas las cosas tienen su lado luminoso y su lado sombrío. 98

Las suicidios:

E1 hombre no es más que un saco de carne que debe llenarse con dineros. Cuando el saco está vacío, no sirve para nada. 99

La tumba es una palma en medio del desierto. Cada sufrimiento, cada congoja, cada angustia es un escalón de esa escala misteriosa vista por Jacob y que nos lleva al cielo.

Las ilusiones son la capa de la vejez. 100

\section{Crónica de mil colores:}

... ese órgano de lujo, que se llama corazón y que es la causa primitiva de todos los males y todas las penas humanas.

A pesar de la revolución que cree torpemente haber abolido para siempre los títulos y señoríos, el hombre que habita el castillo o la mejor casa de campo de una aldea, es siempre el señor a los ojos de los paisanos...

Dos montañas no se encuentran, ... pero dos jóvenes sí se encuentran. 101

\section{Historia de un peso falso:}

... no es nuevo que una señorita bien nacida se fugue con algún pinche de cocina...

Hay hombres que llegan a ministros extranjeros, a ricos, a poetas, a sabios, nada más porque son buenos mozos. $\operatorname{ros} ! 102$

¿Qué afortunados son los pesos falsos y los hombres píca-

Rip-Rip:

El amor es el único que ve a Dios.

Mucho tiempo antes de que uno sepa que es viejo, los demás lo saben $\mathrm{y}$ lo dicen. ${ }^{103}$ 


\section{El vestido blanco:}

"...la humanidad se perpetúa por ineludible ley de ingratitud." 104

Juan el organista:

El tiempo, y sólo el tiempo, ese justiciero inexorable, venga los delitos de leso corazón.

Nada hay tan invencible seductor como una mujer en el abandono de la vida íntima.

... la muerte no se apiada nunca de los infelices. ${ }^{105}$

Dame de coeur:

Nunca nos hace gracia el casamiento de una antigua novia.

Los jugadores no se enmiendan. ${ }^{106}$

Un 14 de julio:

“iMorir! iQué hermosa palabra!" 107

Cwento triste:

Todas las rosas que encontré tenían espinas, y todos los corazones olvido.

La riqueza oculta con su manto de arlequín muchas miserias.

No ambiciones el oro, que es tan frío como el corazón de una coqueta.

Toqué a la puerta de muchos corazones y no me abrieron porque dentro no había nadie. ${ }^{108}$

\section{La novela del tranvía:}

La gente pobre decente es la peor traida y la peor llevada.

Los amigos llegan a cansarse de ayudar al desvalido.

¿Qué cosa es la felicidad? Un poquito de amor, un poquito de salud y un poquito de dinero.

Un espejo es un juez y es un testigo. La mujer que recibe. a su amante viéndose al espejo, es ya la mujer abofeteada de la calle.

Hay besos que se empiezan en la tierra y se acaban en el infierno. 109

\section{La balada de año nuevo:}

“¿Qué es el sabio ante la muerte? La molécula de arena que va a cubrir con su oleaje el océano." 110

La hija del aire:

"La madre es la proyección de Dios sobre la tierra." 111 
Historia de una corista:

"Cuando la mujer se resuelve a hacer de su belleza un negocio por acciones, el mercado mejor es un teatro." 112

Los epigramas de Gutiérrez Nájera, esparcidos en todas las secciones de su producción en prosa, forman como un código de su doctrina filosófica. Los que se contienen en los cuentos, ya presentan la esencia de esta doctrina, ampliada en otras partes.

3. Estilo. Según queda indicado en el capítulo II, Gutiérrez Nájera fué uno de los anunciadores de un movimiento literario: el modernismo, que afectó modos estilísticos, tanto como el encauzamiento de nuevas vías de pensamiento.

Los literatos contemporáneos de Gutiérrez Nájera y los posteriores, discípulos y admiradores influídos por él, se encontraban hajo el hechizo del estilo del Duque, que supo expresar sus pensamientos en metáforas de ricas imágenes.

En 1896, un año después de la muerte de Gutiérrez Nájera, Antonio de la Peña y Reyes caracterizó así su estilo: “... su estilo revestíase a veces de la vaporosa elegancia, de la forma graciosa y otras de la solemne pompa, de la majestad augusta de los buenos hablistas castellanos." 113

Por la misma época, Porfirio Parra expresó su aprecio en forma poética, hablando del conocimiento del Duque de las lenguas española y francesa, que produjeron: “... su estilo, incomparable, rico, fácil, seductor y hermoso, que durante quince años corrió como límpido manantial por el florido valle de las letras mexicanas." 114

También en 1896, Luis G. Urbina comentó acerca de la variedad de estilo del Duque:

Oculto detrás de distintos pseudónimos, tomaba el estilo que mejor cuadraba con el asunto; ya el de la frase galicana, coqueta, frágil y colorida, fresca y empapada en rocío, ya el de las parrafadas españolas, de grave sonoridad, que arrastran manto y caminan majestuosamente. $\mathbf{1 1 5}$

Y Salvador Novo, en sus comentarios a las obras críticas de Gutiérrez Nájera, añade otro matiz, cuando examina su estilo a través del prisma de la preparación de sus lectores: 
...terso y brillante, cosmopolita e intelectual, brunido para lectores que él imaginaba conocedores de lo mejor de la época, de las poesías de Hugo, de las obras de Gautier, de Mendés o de Maupassant. Se siente tan único y tan exclusivo dentro de su época como Melville en Boston, y escribe en un lenguaje para iniciados. 116

Las figuras retóricas de Gutiérrez Nájera llevan el sabor tan personal, que hacen reconocer inequívocamente a su creador $\mathrm{y}$ forman su estilo único y original. Sus símiles, de los que tanto usa $y$, a veces abusa, caracterizan su mundo interior y las tendencias de su pensamiento. En ellos revela su imaginación poética y su propensión de dar cuerpo y alma tanto a los objetos del mundo físico como a las ideas abstractas, a sentimientos esquivos y a sustancias incorpóreas. En sus tropos acude con frecuencia a personificaciones, y en éstas la idea de mujer es casi obsesiva. También utiliza sus amplios conocimientos de literatura clásica y moderna.

En estas páginas destacamos algunas figuras retóricas que abundan en los cuentos de Gutiérrez Nájera, para apreciar sus rasgos.

La venganza de Mylord:

Cuando la tarde se recoge y comienzan a asomarse las estrellas - como se asoman las mujeres al balcón para mirar a sus enamorados- tú buscas la quietud alegre de la casa, abres las cartas de tus amigas, rompes la faja amarilla de los periódicos...

Mira a Clara. Esa es la mujer que no ha amado jamás. Tiene ojos tan profundos y tan negros como el abra de una montaña en nọche obscura. Alli se han perdido muchas almas. De esa obscuridad salen gemidos y sollozos, como de la barranca en que se precipitaron fatalmente los caballeros del Apocalipsis... Su alma es como un cielo sin tempestades, pero sin estrellas... Su corazón es frío como una moneda de oro en día de invierno.

Tras las varillas flexibles del corsé, su corazón late cadenciosamente; i pobre niño que golpea con su manecita una muralla! 117

\section{En el hipódromo:}

El caballo pasea con arrogancia dentro de la pista, como una hermosa en el salón del baile... Y el caballo puede matar a su jinete en el steeple chase, como la dama, por casta y angelical que os parezca, puede también poner en vuestra mano el vibrante florete del duelista o el revólver del suicida. 
Tus pupilas (oh mujer) despiden luces frías, como flechas de acero.

Me han dicho que no debo quererte, y por eso te amo, como José adoraba a Carmen la gitana.

Pero el "Aguila"... llega a la meta, sin una gota de sudor, altiva e impasible como el poeta que, terminada su tragedia, sale al escenario y escucha los aplausos, sin agradecerlos, como no agradece el sol las miradas sumisas de los hombres.

Un grupo de privilegiados se reúne en torno del brasero; ... las llamas rojas salen por los intersticios de la reja, como lenguas de ratones diabólicos que intentan escaparse del infierno. 118

\section{La pasión de Pasionaria:}

¡Cómo se apena el corazón y cómo se entumece el espíritu, cuando las nubes van amontonándose en el cielo, o derraman sus cataratas, como las náyades vertían sus ricas urnas! 119

\section{Después de las carneras:}

Berta dejó que sus trenzas de rubio veneciano le besaran, temblando, la cintura, y apagó con su aliento la bujía, para no verse desvestida en el espejo.

A poco andar dí contra el piano, que se quejó en sí bemol.

Manón es bella, como un lirio enfermo.

Sus pensamientos son como esos rapazuelos encantados que figuran en los cuentos: andan de día con la planta descalza y en camisa; pero dejad que la noche llegue, y miraréis cómo esos pobrecitos limosneros visten jubones de crujiente seda y se adornan con plumas de faisanes.

La seda acaricia como la mano de un amante, y ella sentía un deseo infinito de volver a sentir ese contacto.

Deja que duerma, con su brazo blanco pendiente fuera del colchón, como una virgen que se ha embriagado con el agua de las rosas. 120

\section{Los suicidios:}

Como una dama después del baile, en el misterio de su tocador, iluminado por la discreta luz de sonrosada veladora, se despoja de sus adornos y sus joyas, así me he desvestido de las sencillas creencias de mi infancia. En cada libro, comó las ovejas en cada zarza, he ido dejando, desgarrado, el vellón de la fe. ${ }^{121}$ 


\section{El músico de la murga:}

¡Con qué sandunga y qué malicia canta! ¡Esos ojos sólo salen de noche, porque están prohibidos! Cuando miran es que desnudan la navaja. Los brazos en jarras, parecen decir al majo que los quiere: i Ven a tomarlos!

... ciérranse las vidrieras de colores y esas notas transparentes y frágiles, esas notas que brillan como lágrimas y que suenan como una esquila de cristal, herida por la varita de alguna hada, se pierden y se extinguen poco a poco en la obscuridad, al amanecer... E1 ruiseñor ya no canta; pero el cristal solloza todavía. ${ }^{122}$

\section{Crónica de mil colores:}

Las miradas de ambos jóvenes se cruzaron como un doble fuego de artillería.

Vamos, miedosillo, consolaos y sonreídme, que os veo vuestros lindos dientes más blancos que la leche de mi hermosa vaca negra. 123

Historia de un peso falso:

El caballero se quedó en la fonda meditabundo y triste, ante la taza de té, la copa de Burdeos, ya sin Burdeos y el mesero que estaba parado enfrente de él como un signo de interrogación. Aquella situación no podía prolongarse. Cuando está alguien a solas con una inocente moneda falsa, se avergüenza como si estuviera con una mujer perdida.

Alli, en el zaguán, encogido como un gatito blanco, se quedó el muchacho dormido. Dormido, sí; i pero apretando con los dedos de la mano derecha, que es la más segura, aquel sol, aquella águila, aquel sueño! 124

Rip-Rip:

Parece imposible que tengamos tanta gente y tantas cosas dentro... porque cuando los párpados caen, la mirada, como una señora que cierra su balcón, entra a ver lo que hay en su casa.

Tenía sed... la sed que han de sentir los incendios. ${ }^{125}$

\section{El vestido blanco:}

Mayo, ramillete de lilas húmedas que Primavera prende a su corpiño; Mayo, el de los tibios, indecisos sueños de la pubertad; Mayo, clarín de plata, que tocas diana a los poetas perezosos; Mayo, el que rebosa tantas flores como las barcas de Myssira: tus ojos claros se cierran en éxtasis voluptuoso y se escapa de tus 
labios el prometedor ihasta mañana!, cual mariposa azul de entre los pétalos de un lirio. 126

\section{Juan el organista:}

¡Qué hermosa estaba Enriqueta! Parecía un ángel vestido de sus propias alas.

En esa melodía fugitiva y doliente se revelaba la aflicción de Juan, semejante a un enorme depósito de agua del que sólo se escapa un tenue chorro. Después las ondas armoniosas se encresparon, como un bíblico lago de Tiberiades. El tema principal saltaba en la superficie temblorosa, como la barca de los pescadores sacudida por el oleaje. A veces una ola lo cubría y durante breves instantes quedaba sepultado e invisible. Pero luego, venciendo la tormenta, aparecía de nuevo airoso, joven y gallardo, como un guerrero que penetra, espada en mano, por entre los escuadrones enemigos y sale chorreando sangre, pero vivo. ${ }^{127}$

Dame de coeur:

.. Rosa se vió ataviada para la fiesta y cubierta de flores, como una virgen a quien llevan a enterrar.

La cólera de Rosa-Thé se disipó como las sombras cuando viene el alba. 128

\section{Cuento triste:}

¿Por qué me pides versos? Hace ya tiempo que mi pobre imaginación, como una flor cortada demasiado temprano, quedó en los rizos negros de una espesa cabellera, tan tenebrosa como la noche y como mi alma.

Mi alma es como esos pájaros viejos que no saben cantar y pierden sus plumas una a una, cuando sopla el cierzo de diciembre.

La tarde va a morir: el viento mueve sus alas como un pájaro cansado.

Las ilusiones cantaban en su alma como una bandada de ruiseñores; se casó y la engañaron. 129

\section{Los amores del cometa:}

Venus le provocaba con su voluptuoso parpadeo de media noche, como si ya tuviera sueño y quisiera volver a casa acompañada.

Tuve, pues, que esperarle en pie y armado, como aguarda un celoso al amante de su mujer, para darle, al pasar, las buenas noches. 
La luna, esa gran bandeja de plata en donde pone el sol monedas de oro, se escondía, desvelada y pálida, en Oeste. Los luceros y yo teníamos frío. ${ }^{130}$

\section{La mañana de San Iuan:}

El cielo está inuy limpio, como si los ángeles lo hubieran lavado por la mañana; llovió anoche, y todavía cuelgan de las ramas brazaletes de rocío que se evaporan luego que el sol brilla, como los sueños luego que amanece. 131

\section{La novela del tranvía:}

El cobrador sacude su sombrero, y un benéfico rocío baña las caras de los circunstantes, como si hubiera atravesado por enmedio del vagón un sacerdote repartiendo bendiciones a hisopazos.

... la ciudad de México... Es una gran tortuga que extiende hacia los cuatro puntos cardinales sus patas dislocadas.

Esa mujer es como las papas; no se fíen ustedes, aunque las vean $\tan$ frescas en el agua: queman la lengua. ${ }^{132}$

\section{La balada de año nuevo:}

"Sus cabellos rubios le forman como la aureola de un santito." 133

\section{La hija del aire:}

Es una niña. Sus delgados bracitos van tal vez a quebrarse; su cuello va a troncharse y la cabeza rubia caerá al suelo, como un lirio cuyo delgado tallo tronchó el viento.

A ratos, sólo alcanzo a ver una flotante cabellera rubia, suelta, como la de Ofelia, que da vueltas y vueltas en el aire. 134

\section{Historia de una corista:}

El dinero se iba alejando de mí, como las golondrinas cuando llega el invierno y los amigos cuando llega la pobreza.

Hay hombres que a fuerza de vivir entre panes de azúcar se acostumbran a desmigajar su fortuna como un terrón puesto dentro del agua. ${ }^{135}$ 


\section{RESUMEN}

Dedicamos el capítulo $v$ al estudio de la técnica de los cuentos de Gutiérrez Nájera. En la introducción esbozamos las aptitudes del Duque en el campo de las letras creadoras y establecimos los caracteres del género del cuento, para el que tan buena disposición había en el temperamento de Gutiérrez Nájera. Indicamos temas que atraían su atención, siempre los que conciernen al hombre y a sus problemas emotivos, con tendencia hacia el desenlace trágico $\mathrm{y}$ con arte delicado para pintar el dolor humano.

En el estudio de la construcción de los cuentos pudimos señalar que la anécdota es el elemento secundario y que cede su importancia al análisis de las relaciones humanas, en el que sobresale el Duque.

Fijamos la atención en los recursos de técnica literaria: unidades de lugar, de tiempo y de personaje; suspensión, repetición y puntos de observación, y la trabazón dentro del tema, creando un ambiente personal najeriano.

Después de analizar los tipos de introducciones y conclusiones, continuamos con el estudio de los tipos humanos, estableciendo rasgos comunes entre los protagonistas: hombres, mujeres y niños. Observamos de qué tipos humanos se valió el artista para sus modelos y reconstruímos el concepto de la humanidad, de acuerdo con la imaginación del autor. Señalamos que los hombres de Gutiérrez Nájera tienen una afinidad espiritual con su creador. Para explicar las propensiones de los tipos femeninos, nos servimos de las ideas expresadas por el autor en sus artículos de la serie Crítica social, y vimos que sus niños siempre tienen ciertas características.

Para precisar más la personal aportación de Gutiérrez Nájera hicimos un breve estudio comparativo de su producción con varios cuentos representativos de algunos cuentistas de fama internacional, como Poe, Valera, Stevenson, Maupassant y Chéjov, anotando rasgos de parecido y contraste.

En el análisis de los elementos idiosincrásicos vimos la fértil fantasía imaginativa del escritor, la cual se expresa en la personificación antropomórfica de los fenómenos de la naturaleza y de los objetos del mundo físico, y en el empleo del elemento sobrenatural. 
Finalizamos el capitulo con el estudio de la doctrina filosófica de Gutiérrez Nájera, según se desprende de los epigramas, intercalados en la narración de los cuentos, y de su estilo tan personal, valiéndonos de ejemplos en que las ideas se expresan por medio de figuras retóricas, artísticamente matizadas.

\section{Alexander Kosloff, Los Angeles, California.}

\section{$\mathrm{NOTAS}$}

57 "Juan el organista", op. cit., p. 26.

58 "Crónica de mil colores", op. cit., p. 100.

59 "La novela del tranvía", op. cit., pp. 101-102. Cf. ante, p. 184.

60 Ibid., p. 105. Cf. ante, pp. 186-187.

61 "El matrimonio", "Las mujeres de talento", Obras de Manuel Gutiérrez Nájera, Prosa, crítica social, tomo segundo. (México: Tip. de la Oficina Impresora del Timbre, Palacio Nacional, 1903), pp. 421-426 y 427-431.

62 Ibid. ("El matrimonio"), p. 423.

63 Loc. cit.

64 Ibid., p. 424.

65 Ibid. ("Las mujeres de talento"), pp. 428-429.

66 Ibid., p. 429.

67 Loc. cit.

68 Ibid., pp. 429-430.

69 Ibid., p. 430.

$70 \quad$ Ibid., pp. $430-431$.

71 Ibid., p. 431.

72 Loc. cit.

73. "La hija del aire", Manuel Gutiérrez Nájera, Cuentos Frágiles, op. cit., p. 121. Cf. ante, p. 160. 
74 "Historia de un peso falso", Obras de Manuel Gutiérrez Nájera, Prosa, cuentos color de humo, tomo primero, op. cit., pp. 114-115. Cf. ante, pp. 132-133.

75 Ibid., D. 114.

76 "El vestido blanco", op. cit., p. 19.

77 "Juan el organista", op. cit., pp. 31-32.

78 "La mañana de San Juan", Manuel Gutiérrez Nájera, Cuentos Frágiles, op. cit., p. 93.

79 Ibid., p. 94.

80 "La balada de año nuevo", op. cit., p. 111.

81 Ibid., p. 114.

82 "La hija del aire", op. cit., p. 120.

83 Cf. ante, p. 108.

84 Para el contenido de estos cuentos, $C f$. Apéndice de la tesis, pp. 317338.

85 Cf. pp. 133-142 y 188-201.

$86 C f$. Apéndice, pp. 333-335.

$87 C f$. Apéndice, p. 336.

88 Cf. pp. 112-113 de la tesis.

89 Cf. p. 129.

90 Cf. pp. 176-177.

91 Cf. pp. 195-196.

92 Loc, cit.

.93 Cf. ante, pp. 12-15.

94 Luis G. Urbina, "Confidencias" (a Carlos Diaz Dufóo), Revista azul, (México), $4: 220$, febrero 2, 1896.

95 "La venganza de Mylord", Obras de Manuel Gutiérrez Nájera, Prosa, cuentos frágiles, tomo primero, op. cit., pp. 12, 16.

96 "En el hipódromo", Obras de Manuel Gutiérrez Nájera, op. cit., p. 22.

97 "La pasión de Pasionaria”, loc. cit. 
98 "Después de las carreras", Obras de Manuel Gutiérrez Nájera, op. cit., p. 40 .

99 Hay un epigrama de sentido opuesto en otra parte, que dice: "La fe es la mano que está tendida siempre, el bolsillo que nunca se vacía, el corazón que eternamente late." "La fiesta de la Virgen", Obras de Manuel Gutiérrez Nájera, Prosa, crónicas y fantasías, tomo primero, op. cit., pp. 162-163.

100 "Los suicidios", op. cit., pp. 50, 51.

101 "Crónica de mil colores", op. cit., pp. 101, 102.

102 "Historia de un peso falso", op. cit., pp. 111, 113, 114.

103 "Rip-Rip", op. cit., pp. 5, 6.

104 "El vestido blanco", op. cit., p. 20.

105 "Juan el organista", op. cit., pp. 31, 38, 41.

106 "Dame de coeur", Manuel Gutiérrez Nájera, Cuentos color de humo, op. cit., p. 50 .

107 “Un 14 de julio", op. cit., p. 63.

108 "Cuento triste", op. cit., pp. 69, 70, 73.

109 "La novela del tranvía”, op. cit., pp. 102, 103, 108.

110 "La balada de año muevo", op. cit., p. 115.

111 "La hija del aire", op. cit., p. 121.

112 "Historia de una corista", op. cit., p. 130.

113 Antonio de la Peña y Reyes, artículo, Revista azul, $4: 219$, febrero 2, 1896.

114 Porfirio Parra, "Manuel Gutiérrez Nájera”, Revista azul, 4:299, marzo 8, 1896.

115 Urbina, loc. cit., pp. 27-28.

116 Salvador Novo, Prólogo a Manuel Gutiérrez Nájera: Prosa selecta, (México: W. M. Jackson, Inc., Editores, 1948), p. 9.

117 "La venganza de Mylord", op. cit., pp. 11, 12, 13.

118 "En el Hipódromo", op. cit., pp. 22, 23, 24.

119 "La pasión de Pasionaria", op. cit., p. 28.

120 "Después de las carreras", op. cit., pp. 37, 38, 39, 40, 41, 42. 
121 "Los suicidios", op. cit., p. 51.

122 "El músico de la murga", op. cit., pp. 89, 89-90.

123 "Crónica de mil colores", op. cit., pp. 102, 105.

124 "Historia de un peso falso", op. cit., pp. 112, 116.

125 "Rip-Rip", op. cit., pp. 5, 11.

126 "E1 vestido blanco", op. cit., p. 15.

127 "Juan el organista", op. cit., pp. 43-44, 44.

128 "Dame de coeur", op. cit., pp. 53, 54.

129 "Cuento triste", op. cit., pp. 69, 70-71, 71.

130 "Los amores del cometa", op. cit., pp. 79, 81, 82.

131 "La mañana de San Juan", op. cit., p. 89.

132 "La novela del tranvía", op. cit., pp. 99-100, 100, 105.

133 "La balada de año nuevo", op. cit., p. 113.

134 "La hija del aire", op. cit., p. 120.

135 "Historia de una corista", op. cit., p. 131. 
